Lepr Rev (1999) 70, 136-139

\title{
Science Commentary
}

\section{How Mycobacterium leprae infects peripheral nerves}

\author{
VICTORIA H. FREEDMAN*, DAVID E. WEINSTEIN** \\ \& GILLA KAPLAN* \\ *Laboratory of Cellular Physiology and Immunology, \\ The Rockefeller University, 1230 York Avenue, New York, \\ NY 10021, USA \\ **Departments of Neuroscience, Pathology and the Comprehensive \\ Cancer Center, Albert Einstein College of Medicine, 1300 Morris \\ Park Avenue, Bronx, NY 10461, USA
}

It has long been known that leprosy is an infection of the peripheral nerves. Even when only limited numbers of skin lesions are present and only small numbers of Mycobacterium leprae are found in the skin, the organisms preferentially localize to the peripheral nerves. Histologically, bacilli are seen in intracellular vacuoles of either myelinating Schwann cells $^{1}$ or in macrophages which have migrated from the blood into the perineural space. Infection of the nerves can result in chronic demyelination/remyelination, of ten leading to calcification and permanent loss of neural function. ${ }^{2}$ Because of this, leprosy is the leading cause of non-traumatic peripheral neuropathy. ${ }^{3}$ Although it is clear that the Schwann cells are the main targets of $M$. leprae infection, the molecular basis of this tropism, and how the organism gains entry into the nerve and then into the Schwann cells, was not known.

The field of leprosy research has now been excited by two recent papers by Rambukkana et al. ${ }^{4,5}$ in which the investigators describe a molecular mechanism for the selective affinity of $M$. leprae for Schwann cells. The studies have identified a glycoprotein which binds to ('opsonizes') the surface of $M$. leprae which is in turn bound by a molecule on the Schwann cell surface (a 'receptor'), thereby providing a potential mechanism for internalization of the bacilli by Schwann cells.

The Schwann cell/axon unit of peripheral nerves is covered by a basal lamina (Figure 1) which consists of a number of extracellular matrix molecules, including laminins, type IV collagen, entactin/nidogen, and heparin-sulphate proteoglycans. ${ }^{6,7}$ The laminins are glycoproteins composed of three chains, $\alpha, \beta$, and $\gamma$. There are 11 distinct isoforms depending on the configuration of the chains. In the Schwann cell basal lamina of the peripheral nerve, the predominant form is laminin-2, which is composed of the $\alpha 2, \beta 1$, and $\gamma 1$ chains. ${ }^{8}$ This configuration is not found in the central nervous system. In their first paper, Rambukkana et $a l .^{4}$ showed that $M$. leprae binds specifically to the G-domain, which is located at the C-terminal end of the $\alpha 2$ chain of laminin-2.

Correspondence to: G. Kaplan 


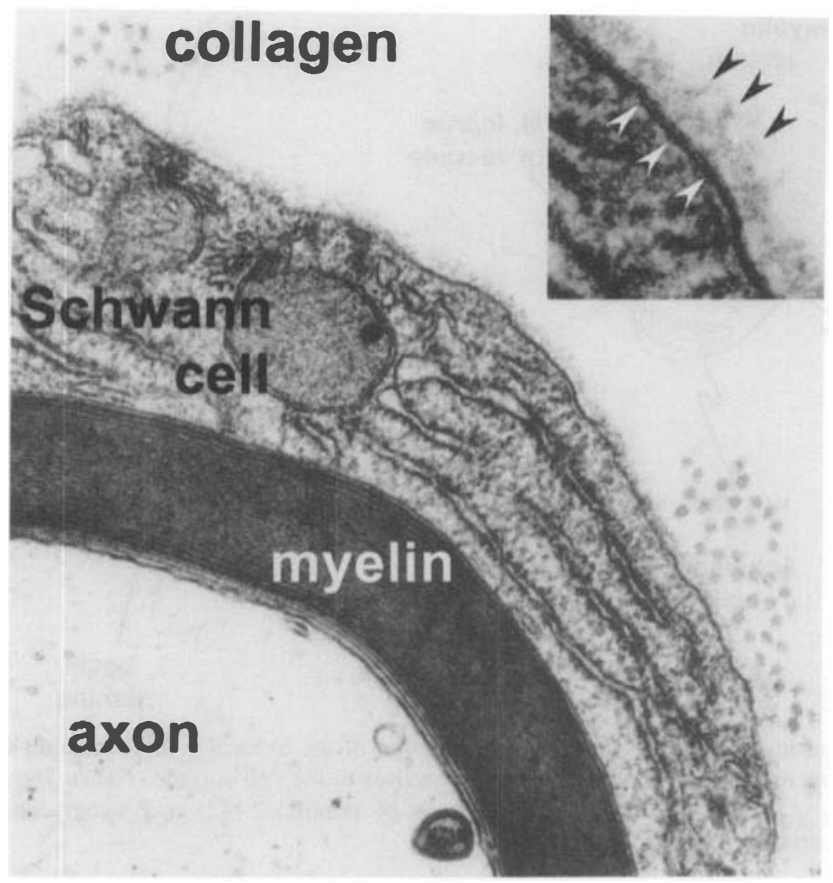

Figure 1. Electron micrograph of a myelinating Schwann cell/axon unit of a peripheral nerve. The axon surrounded by a myelin sheath of the Schwann cell is shown. On the surface of the cell the basal lamina can be seen. Collagen fibres (in cross section) are present in the extracellular space. The insert shows a higher magnification of the cell membrane (white arrowheads) covered by the basal lamina (dark arrowheads). Magnification $\times 36,400$; insert, $\times 180,000$.

Schwann cells express on their surface proteins which can mediate binding to components of the extracellular matrix of the basal lamina. $\alpha$-Dystroglycan is one such protein. ${ }^{9}$ The dystroglycans of Schwann cells are encoded in one transcript and then cleaved resulting in an extracellular portion, $\alpha$-dystroglycan, and a transmembrane portion, $\beta$-dystroglycan. In the second paper, Rambukkana et al. ${ }^{5}$ showed that M. leprae bound to the $\mathrm{G}$ domain of laminin2 , is in turn bound to $\alpha$-dystroglycan on the Schwann cell surface. $\alpha$-Dystroglycan bound to laminin-2/M. leprae is associated with the transmembrane molecule $\beta$-dystroglycan. At an intracellular binding site, $\beta$-dystroglycan binds to dystrophin, an intracellular protein which in turn binds to actin. ${ }^{10}$ These four proteins (laminin-2, $\alpha$-dystroglycan, $\beta$-dystroglycan, dystrophin) thus provide a bridge between $M$. leprae and the internal environment (the cytoskeleton) of the Schwann cell (Figure 2). Subsequent to binding on the cell surface of the Schwann cell, Rambukkana et al. ${ }^{5}$ observed clustering of the $\alpha$-dystroglycan/M. leprae complexes, which presumably leads to internalization of the bacilli into a cytoplasmic vacuole and establishment of Schwann cell infection.

This raises the question as to how $M$. leprae gains access to the peripheral nerve. It is likely that infected blood monocytes from broken skin or mucous membranes transport the bacilli into the naive nerve during the normal trafficking of macrophages through the peripheral nervous system. This type of trafficking occurs in all individuals, as a low, steady state monocyte exchange between nerves and blood. ${ }^{11}$ However, in an M. leprae infected individual, it is possible that an infected macrophage might enter a nerve and be trapped 


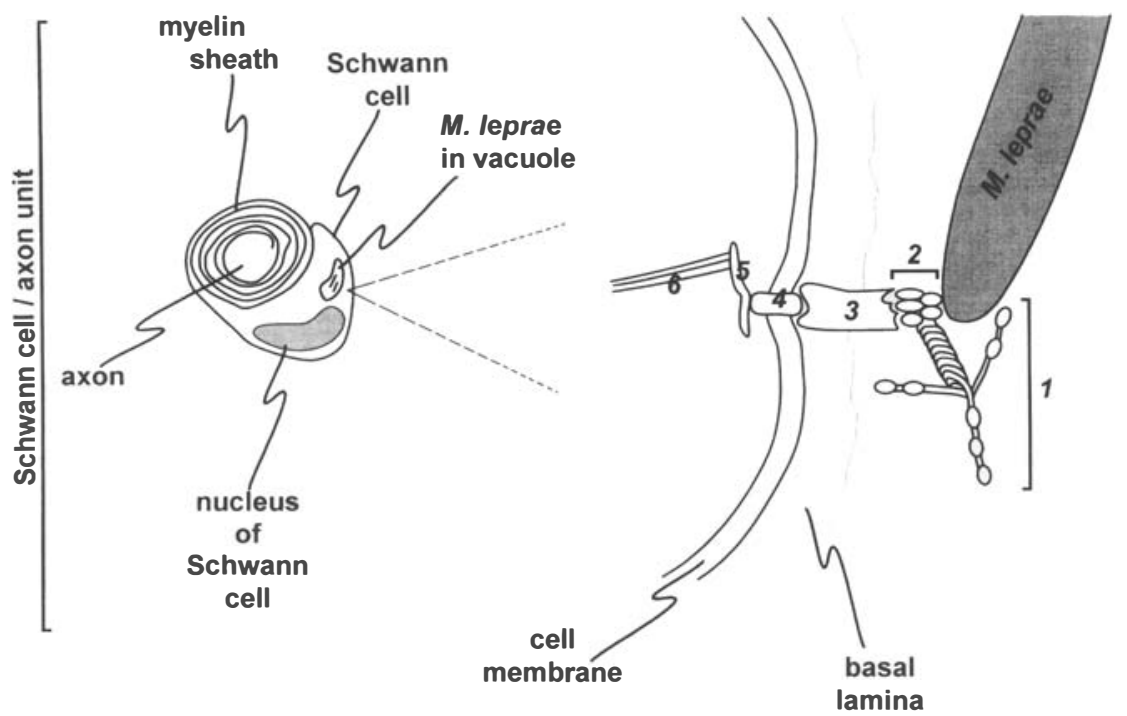

Figure 2. A schematic representation of $M$. leprae infection of the Schwann cell/axon unit (left) and an enlarged diagram of the proteins involved in the binding of the bacillus to the cell surface (right). The numbers in the figure denote the following: (1) laminin-2; (2) $\alpha-2 \mathrm{G}$ domain of laminin-2; (3) $\alpha$-dystroglycan; (4) $\beta$-dystroglycan; (5) dystrophin; (6) actin cytoskeleton.

there. When the load of replicating organisms ultimately leads to destruction of the cell, the bacilli would be released into the endoneureal space. The mycobacteria would then be bound by laminin $\alpha$-2, which would tether them to the $\alpha$-dystroglycan on the surface of myelinating Schwann cells. Internalization would then occur. Infected Schwann cells would degenerate, increasing recruitment of macrophages into the nerve. ${ }^{12}$ Because $\alpha-2$ laminin and the $\alpha$-dystroglycan are restricted to peripheral nerves, M. leprae infection would not occur in the central nervous system.

Leprosy has long-term sequelae, which persist despite successful antibiotic treatment and microbiological cure of the infection. In millions of individuals, intractable peripheral neuropathies ensue. ${ }^{13}$ These complications are difficult to manage clinically, at least in part because we do not understand the underlying mechanisms of pathogenesis. Such understanding requires more research. Studies such as those reported by Rambukkana et al. ${ }^{4,5}$ illuminate a mechanism of leprosy pathogenesis and may result in new interventions to treat and/or prevent nerve damage. Unfortunately, the perception that leprosy is no longer a significant disease has resulted in a virtual elimination of funding for leprosy research. The investigations described here, elucidating the molecular events of leprosy infection of peripheral nerves, illustrate the potential usefulness and importance of continuing research in leprosy.

\section{References}

1 Stoner GL. Importance of the neural predilection of Mycobacterium leprae in leprosy. Lancet, 1979; 2: 994-996.

2 Sabin TD, Swift TR, Jacobson RR. Leprosy. In: Dyck PKTPJ, Lambert EH, Bunge R, eds. Peripheral neuropathy. W. B. Philadelphia: Saunders, 1984. 
${ }^{3}$ Nations SP, Katz JS, Lyde CB, Barohn RJ. Leprous neuropathy: an American perspective. Semin Neurol, 1998; 18: $113-124$.

${ }^{4}$ Rambukkana A, Salzer JL, Yurchenco PD, Tuomanen EI. Neural targeting of Mycobacterium leprae mediated by the $\mathrm{G}$ domain of the laminin-alpha 2 chain. Cell, 1997; 88: 811-821.

5 Rambukkana A, Yamada H, Zanazzi G, Mathus T, Salzer JL, Yurchenco PD, Campbell KP, Fischetti VA. Role of alpha-dystroglycan as a Schwann cell receptor for Mycobacterium le prae. Science 1998; 282: 2076-2079.

${ }^{6}$ Bunge MB, Williams AK, Wood PM. Neuron-Schwann cell interaction in basal lamina formation. Dev Biol, 1982; 92: 449-460.

${ }^{7}$ Cornbrooks CJ, Carey DJ, McDonald JA, Timpl R, Bunge RP. In vivo and in vitro observations on laminin production by Schwann cells. Proc Natl Acad Sci USA, 1983; 80: 3850-3854.

8 Villanova M, Sewry C, Malandrini A, Toti P, Muntoni F, Merlini L, Torelli S, Tosi P, Maraldi NM, Guazzi GC. Immunolocalization of several laminin chains in the normal human central and peripheral nervous system. J Submicrosc Cytol Pathol, 1997; 29: 409-413.

9 Matsumura K, Chiba A, Yamada H, Fukuta-Ohio H, Fujita S, Endo T, Kobata A, Anderson LV, Kanazawa I, Campbell KP, Shimizu T. A role of dystroglycan in schwannoma cell adhesion to laminin. J Biol Chem, 1997; 272: $13904-13910$.

10 Yamada H, Chiba A, Endo T, Kobata A, Anderson LV, Hori H, Fukuta-Ohi H, Kanazawa I, Campbell KP, Shimizu T, Matsumura K. Characterization of dystroglycan-laminin interaction in peripheral nerve. $J$ Neurochem, 1996; 66: 1518-1524.

11 Oldfors A. Macrophages in peripheral nerves. An ultrastructural and enzyme histochemical study on rats. Acta Neuropathol (Berl), 1980; 49: 43-49.

12 Griffin JW, George EB, Chaudhry V. Wallerian degeneration in peripheral nerve disease. Bailliere's Clin Neurol, 1996; 5: 65-75.

${ }^{13}$ Pfatzgraff RF, Bryceson A. Clinical leprosy. In: Leprosy. New York: Churchill Livingstone, 1985. 